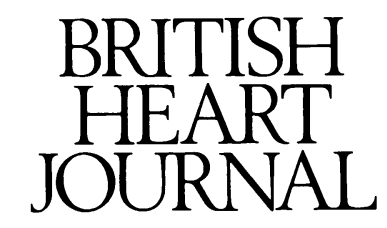

\title{
Editorial
}

\section{Surgery for atrial fibrillation}

A self confessed "former" arrhythmia surgeon has recently written that "the golden era of arrhythmia surgery for supraventricular arrhythmias has passed". ${ }^{1} \mathrm{He}$ rightly attributes the end of this era (which lasted only 20 years from the first description of surgical ablation of an accessory pathway) to the advent of catheter ablation and to the development of safer energy sources and better catheters. He also hopes that catheterisation techniques will be developed that will supersede recently described surgical operations to prevent atrial fibrillation. ${ }^{1}$

Surgery directed specifically at atrial fibrillation (rather than at its cause-for example, mitral valve disease) was initially aimed at interrupting atrioventricular (AV) conduction and thus controlling the ventricular response. ${ }^{2}$ AV node ablation is now more commonly performed using percutaneous catheterisation techniques; and surgery for AV node ablation is performed either in conjunction with other surgery-for example, mitral valve replacement-or as a last resort.

More recently, specific operations for the treatment of atrial fibrillation refractory to medical treatment have been described. These operations are alternatives to AV node ablation with permanent ventricular pacing.

\section{The corridor operation}

Guiraudon devised the corridor operation, which isolates an atrial corridor consisting of the sinus node area, the $\mathrm{AV}$ nodal junction, and the connecting right atrial mass (fig 1)..$^{3-5}$ This is designed to preserve sinus node function and hence physiological control of heart rate.

Two series of patients treated with the corridor operation have been described. Leitch et $a l^{3}$ reported their results in nine patients. One patient required reoperation for early recurrence of atrial fibrillation. At postoperative electrophysiological study the corridor was shown to be electrically isolated from the atria in eight of nine; one patient had a junctional rhythm in the corridor connected to the AV node and so to the ventricles, one had atrial tachycardia, and one had atrial fibrillation/flutter. Sinus node function was abnormal in all, and pacemakers were implanted in four. Two have had late atrial arrhythmias.

Defauw et $a l^{4}$ and van Hemel et $a l^{5}$ described 36 patients, with permanent success in $24(67 \%)$. Nine (25\%), however, required repeat operation, which failed in five. Paroxysmal atrial arrhythmias occurred in the corridor in six of the 27 deemed successful $(22 \%)$. Five patients in whom the second operation also failed subsequently underwent His bundle ablation with rate responsive ventricular pacing. Five patients with sinus node dysfunction also received pacemakers. Thus $28 \%$ required pacing. One patient had an early postoperative stroke and a second had a stroke 4 months later. During long-term follow up (mean 41 months) six of 31 had attacks of atrial flutter requiring antiarrhythmic drugs.

So far, nine (31\%) of 29 patients undergoing the corridor operation have required early reoperation for recurrent arrhythmias. Atrial arrhythmias may also recur later; they were seen in at least eight $(22 \%)$ of 45 . Postoperatively, sinus node dysfunction is common and permanent pacing may be required (in $32 \%$ ). Atrial transport is not restored, and atrial thrombus and embolism presumably remain risks.

\section{The maze operation}

Pierce and Sobel described the maze operation as a "brilliant advance in surgery". ${ }^{6}$ It was introduced and advocated by Cox et al. ${ }^{7}$ The operation was designed to interrupt all potential reentrant circuits, while maintaining AV synchrony, so preserving both physiological control of heart rate and atrial contraction and thus reducing the risks of thrombosis and embolism.?

Cox and his colleagues have clearly described the rationale for and evolution of this surgical technique. ${ }^{89}$ Both atria are precisely incised so that the impulse can

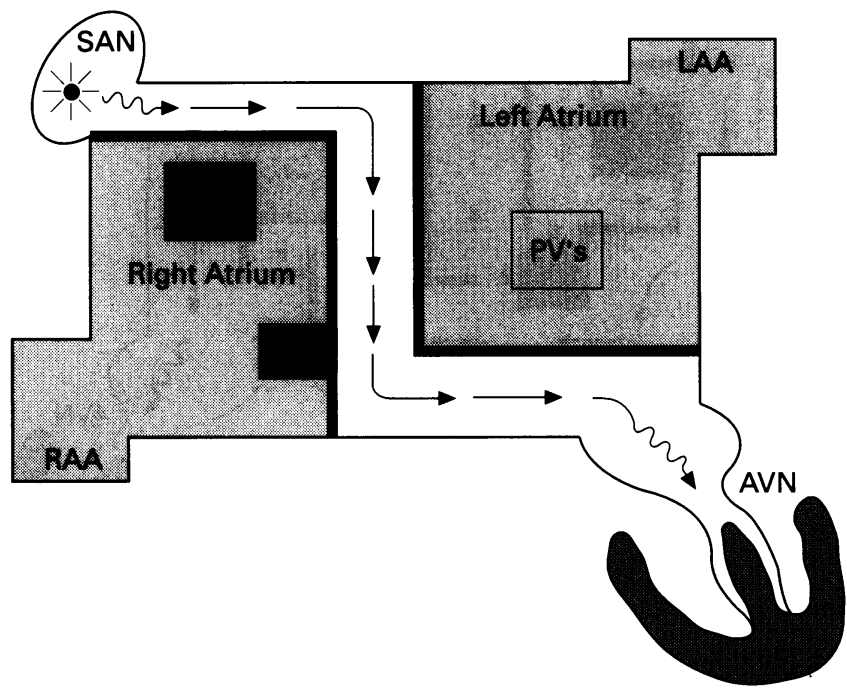

Figure 1 Schematic representation of the results of the corridor procedure for the surgical treatment of atrial fibrillation. Technically speaking, a sinus rhythm may follow this procedure in that the sinus node impulse drives the ventricles. However, because of loss of both right atrial and left atrial synchrony with the respective ventricles, the haemodynamic abnormalities associated with atrial fibrillation are not improved. In addition, the vulnerability to the development of left atrial thrombi is not alleviated. $A V N$, atrioventricular node; $L A A$, left atrial appendage; $P V$, pulmonary veins; $R A A$, right atrial appendage; $S A N$, sinoatrial node. Reproduced with the permission of the fournal of Thoracic and Cardiovascular Surgery. ${ }^{7}$ 
still propagate from the sinoatrial node to the atrioventricular node after surgical repair of the several incisions, and so that the atrial mass in continuity is insufficient to maintain atrial fibrillation (fig 2). Results have been reported in 75 patients from the St Louis group to date. ${ }^{70-13}$ Their early experience has been reported extensively. ${ }^{70-12}$ The mean cardiopulmonary bypass time in those not undergoing concomitant surgery was 184 (range 130-256) minutes with a mean aortic cross clamp time of $69(50-102)$ minutes. ${ }^{13}$ There was one operative death among the first 75 patients. Serious postoperative morbidity occurred, particularly in those who had undergone previous cardiac surgery and included postoperative biventricular assist and intra-aortic balloon pumping in one, re-exploration for bleeding in $7 \%$, pancreatitis in $4 \%$, and cerebrovascular embolism in $4 \%$ (transient ischaemic attacks in 3\%). During the first three months after surgery, $47 \%$ of the patients had either atrial flutter or fibrillation. Forty percent of the patients who had been followed up for three months or more required permanent pacemakers postoperatively. Of these, $17 / 26$ (65\%), a surprisingly high proportion, had been shown by preoperative electrophysiological studies to have sinus node dysfunction, five already had pacemakers, and four were said to have sustained damage to the sinus node intraoperatively. Atrial flutter could be induced three or more months postoperatively in $6 \%$. Atrial flutter has occurred spontaneously in eight patients (12\%) and atrial fibrillation had recurred in one patient. Seven patients $(11 \%)$ were taking antiarrhythmic drugs for atrial arrhythmias more than three months after operation.

Preservation of atrial transport function was demonstrated by echocardiography and by Doppler studies both early and late. ${ }^{72-14}$

The Cleveland Clinic experience was described by McCarthy et al. ${ }^{15-17}$ Fourteen patients underwent surgery: one patient had a perioperative stroke and one patient

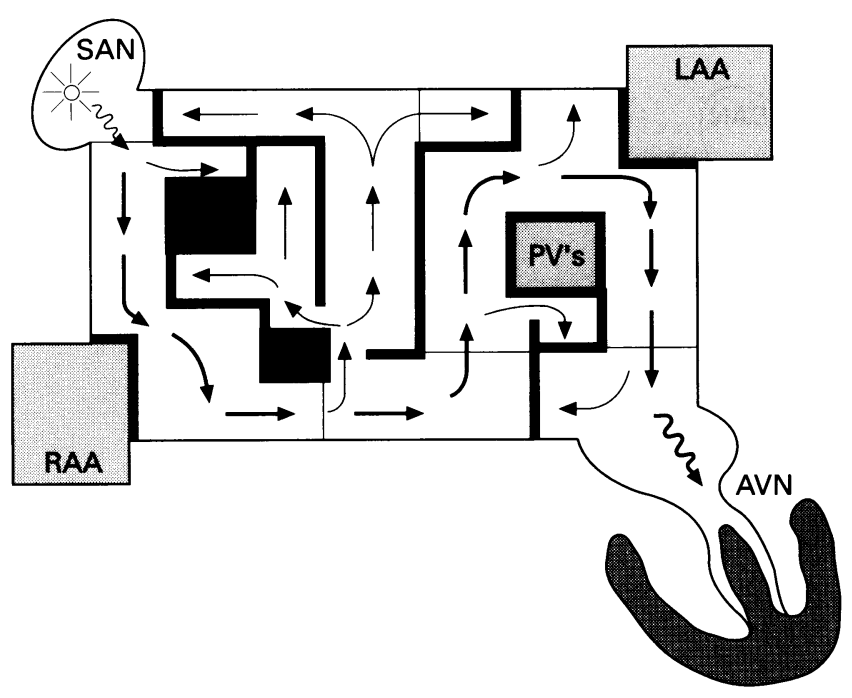

Figure 2 Maze procedure for atrial fibrillation. Because atrial fibrillation is characterised by the presence of multiple macroreentrant circuits that are fleeting in nature and can occur anywhere in the atria, a surgical procedure based on the principle of a maze was developed. Both atrial appendages are excised and the pulmonary veins are isolated. Appropriately placed atrial incisions not only interrupt the conduction routes of the most common reentrant circuits, but they also direct the sinus impulse from the $S A$ node to the $A V$ node along a specified route. The entire atrial myocardium (except for the atrial appendages and pulmonary veins) is electrically activated by providing for multiple blind alleys off the main conduction route between the $S A$ node and the $A V$ node, thereby preserving atrial transport function postoperatively. See fig 1 for abbreviations. Reproduced with the permission of the fournal of Thoracic and Cardiovascular Surgery. died within 30 days. Mean cardiopulmonary bypass time in all patients was $143(117-172)$ minutes and mean aortic cross clamp time was 69 (47-98) minutes (mean 139 and 66 minutes without concomitant surgery). The initial postoperative rhythm was junctional, but sinus rhythm resumed. Two patients had perioperative sick sinus syndrome and received dual chamber rate responsive pacing. Six patients $(43 \%)$ had postoperative atrial fibrillation and others had transient atrial fibrillation or flutter. There was no recurrence of atrial fibrillation after the first three months. ${ }^{17}$ Other reports describe few ${ }^{18}$ or individual patients. ${ }^{19-21}$

An interesting complication recognised by both groups ${ }^{101317}$ is the tendency to retain excessive fluid postoperatively. Cox et al ${ }^{10} 13$ reported pulmonary oedema in $71 \%$ of their early patients and attributed this to a decrease in atrial natriuretic peptide. Subsequently, routine administration of spironolactone prevented pulmonary oedema. ${ }^{13}$ McCarthy et al reported pleural effusions or peripheral oedema or both in $36 \%$ of their patients. ${ }^{17}$

So far, 95 patients undergoing the maze operation have been described. Operative mortality is $2 \%$ and postoperative morbidity is not uncommon. Atrial arrhythmias occur in about half in the first three postoperative months, but seem to cease after this. Sinus node dysfunction is common and permanent pacing may be required in up to half. Atrial transport is restored, and atrial thrombus and embolism are thought not to remain risks. Cox et al no longer routinely use anticoagulation postoperatively. ${ }^{13}$

Postoperative sinus node dysfunction has been studied in detail in dogs by McLoughlin et al. ${ }^{22}$ Sinus node dysfunction occurred acutely in all 17 animals after the maze operation. Sinus node function tended to return to nor$\mathrm{mal}$ in the succeeding 6 months, but remained abnormal compared with preoperative values. Postoperative arrhythmias were observed in nine $(53 \%)$ of 17 and were mainly bradycardias. Only five (29\%) of 17 survived between 90 and 180 days. No reason was given for this.

Cox's original technique is already being modified, ${ }^{11} 17182123$ specifically in an attempt to minimise surgical trauma to the sinus node, ${ }^{17}$ to preserve its blood supply, ${ }^{17}$ and to reduce potential technical difficulties. ${ }^{18}$

Thus surgery specifically directed at atrial fibrillation has been devised and described. Neither Guiraudon's corridor operation ${ }^{3-5}$ nor Cox's maze operation ${ }^{7-14162324}$ have been performed in many patients or by many surgeons. The results described are necessarily preliminary and short term. There is concern about high morbidity, particularly after the maze operation; need for a second operation, particularly after the corridor operation (although this perhaps represents relative inexperience); and recurrent atrial arrhythmias, not necessarily fibrillation. The high requirement for pacing postoperatively is also a concern: it is due in part to preoperative sinus node function, to intraoperative trauma, and to devascularisation of the sinus node, and in part to surgical failure and subsequent treatment by $\mathrm{AV}$ node or His bundle ablation. The maze operation has been described with great enthusiasm ${ }^{6}$-it has the advantage over the corridor operation that it may preserve atrial transport ${ }^{24}$; the price, however, is sinus node dysfunction and permanent pacing in about half the patients. It is reassuring that a second group has achieved similar results. ${ }^{15-17}$ However, until the presumed long-term benefits of such surgery, including preservation of atrial transport and lack of requirement for anticoagulation, can be demonstrated it might be argued that His bundle ablation and permanent rate responsive pacing has similar results, lower morbidity, 
and costs less. It remains to be seen whether the maze operation is in fact a surgical cure for medically refractory atrial fibrillation, ${ }^{13}$ or whether it becomes, as has already been advocated, a prophylactic procedure in those predisposed to atrial fibrillation. ${ }^{23}$ If it is a cure, other "former" arrhythmia surgeons may also find a new role. ${ }^{11920}$

Regional Cardiothoracic Centre,

JANET M MCCOMB

Freeman Hospital,

Newcastle upon Tyne NE7 7DN

1 Brodman R. Catheter ablation: a "former" arrhythmia surgeon's view. PACE 1992;15:1231-2.

2 Sealy WC, Gallagher J, Kasell J. His bundle interruption for control of inappropriate ventricular responses to atrial arrhythmias. Ann Thorac inappropriate ventricula

3 Leitch JW, Klein G, Yee R, Guiraudon G. Sinus node-atrioventricular node isolation: long-term results with the "corridor" operation for atrial fibrillation. F Am Coll Cardiol 1991;17:970-5.

4 Defauw JAMT, Guiraudon GM, van Hemel NM, Vermeulen EE Kingma JH, de Bakker JMT. Surgical therapy of paroxysmal atria fibrillation with the "corridor" operation. Ann Thorac Surg 1992;53 564-71.

5 van Hemel NM, Defauw JJAMT, Kingma JH, Jaarsma W, Vermeulen FEE, de Bakker JMT, Guiraudon GM. Long-term results of the corridor operation for atrial fibrillation. $B r$ Heart $\mathcal{f} 1994 ; 71: 170-6$.

6 Pierce JA, Sobel BE. Frontiers in surgery: a perspective. $\mathscr{F} A M A 1991 ; 266$ : 1990-2.

7 Cox JL, Schuessler RB, D'Agostino HJ Jr, Stone CM, Chang BC, Caine ME, Corr PB, Boineau JP. The surgical treatment of atrial fibrillation (III) Development of a definitive surgical procedure. $\exists$ Thorac Cardiovasc Surg 1991;101:569-83.

$8 \mathrm{Cox} \mathrm{JL}$. The surgical treatment of atrial fibrillation. (IV) Surgical technique. $\mathcal{F}$ Thorac Cardiovasc Surg 1991;101:584-92.

9 Stone CM, Chang BC, Tweddell JS, Sato S, Schuessler RB, Barzilai B Boineau JP, Cox JL. Ablation of atrial fibrillation by the maze procedure. Surg Forum 1989;40:213-5.

10 Cox JL, Boineau JP, Schuessler RB, Ferguson TB, Caine ME, Lindsay BD, Corr PB, Kater KM, Lappas DG. Successful surgical treatment of atrial fibrillation: review and clinical update. $f A M A$ 1991;266:1976-80.
11 Cox JL, Boineau JP, Schuessler RB, Ferguson TB, Caine ME, Lindsay BD, Corr PB, Kater KM, Lappas DG. Operations for atrial fibrillation. Clin Cardiol 1991;14:827-34.

12 Cox $\mathrm{L}$, Boineau JP, Schuessler RB, Ferguson TB, Lindsay BD, Caine ME, Corr PB, Kater KM, Lappas DG. A Review of surgery for atrial ME, Corr PB, Kater KM, Lappas DG. A Review of
fibrillation. f Cardiovasc Electrophysiol 1991;2:541-61.

13 Cox JL, Bioneau JL, Schuessler RB, Kater KM, Lappas DG. Five year experience with the maze procedure for atrial fibrillation. Ann Thorac Surg 1993;56:814-2

14 Hand DE, Lappas DG, Hogue CW, Cox JL. Perioperative transesophageal doppler echocardiographic verification of atrial transpor function following the maze procedure for atrial fibrillation. Surg Forum 1992;43:267-9.

15 McCarthy PM, Cosgrove DM, Castle LW, White RD. Combined treatment of mitral regurgitation and atrial fibrillation with valvuloplasty and the maze procedure. Am $\mathcal{F}$ Cardiol 1993;71:483-6.

16 McCarthy PM, Castle LW, Trohman RG, Simmons TW, Maloney JD, Klein AL, White RD, Cox JL. The maze procedure: surgical therapy for refractory atrial fibrillation. Cleve Clin f Med 1992;60:161-5.

17 McCarthy PM, Castle LW, Maloney JD, Trohman RG, Simmons TW, White RD, Klein AL, Cosgrove DM. Initial experience with the maze procedure for atrial fibrillation. F Thorac Cardiovasc Surg 1993;105: procedure

18 Johnson DC. Early experience with the modified maze operation for atrial fibrillation with and without mitral valve surgery. Australas $\mathcal{f}$ Cardiac Thorac Surg 1992;1:13-6.

19 Blitz A, McLoughlin D, Gross J, Schwartz DS, Fisher JD, Kim SG, Frame R, Brodman R. Combined maze procedure and septal myomectomy in a septuagenarian. $\mathcal{F}$ Thorac Surg 1992;54:364-5

20 Bonchek LI, Burlingame MW, Worley SI, Vazales BE, Lundy EF. Cox/maze procedure for atrial septal defect with atrial fibrillation: management strategies. Ann Thorac Surg 1993;55:607-10.

21 Hioki M, Ikeshita M, Iedokoro Y, Nitta T, Harada A, Asano T, Tanaka S, Shoij T. Successful combined operation for mitral stenosis and atrial fibrillation. Ann Thorac Surg 1993;55:776-8.

22 McLoughlin DE, Blitz A, Simmons J, Brodman R, Frame R, Bator S, Adams J, Schwartz DS, Furman S, Fisher JD. Electrophysiological Adams J, Schwartz DS, Furman S, Fisher JD. Electrophysiological PACE 1992;15:2084-91.

23 Cox JL. Evolving applications of the maze procedure for atrial fibrillation. Ann Thorac Surg 1993;55:578-80.

24 Cox JL. (discussion of Defauw JAMT, Guiraudon GM, van Hemel NM, Vermeulen EE, Kingma JH, de Bakker JMT. Surgical therapy of paroxysmal atrial fibrillation with the "corridor" operation) Ann Thorac Surg 1992;53:571. 